\title{
A LINGUAGEM DO MOVIMENTO NA EDUCAÇÃO INFANTIL E A CONSTRUÇÃO DA PROFISSIONALIDADE DOCENTE
}

\author{
Amanda Pires Chaves \\ Universidade Estadual Paulista - UNESP, Educação Física, Presidente Prudente, SP. UNINTER, Metodologia do Ensino \\ da Educação Física. Universidade Estadual de Londrina - UEL, Educação, Londrina, PR. Universidade de Sorocaba - \\ UNISO, Programa de Pós-Graduação em Educação. E-mail: amanda.pireschaves@gmail.com
}

\section{RESUMO}

Este artigo, caracterizado como revisão bibliográfica, tem a pretensão de contribuir com reflexões e discussões acerca dos processos de formação inicial de professores de Educação Infantil e da construção da profissionalidade docente, tendo como foco específico, a linguagem do movimento, um dos saberes necessários e indispensáveis ao exercício docente neste âmbito educacional. Segundo autores como Pinto (2001), Cavalaro e Muller (2009), no contexto atual, os cursos de formação de professores para a Educação Infantil apresentam pouca ou nenhuma discussão acerca da linguagem do movimento. E, ainda, não é estabelecido pelas legislações a que profissional compete exercer a disciplina de Educação Física na Educação Infantil, relacionada de modo mais próximo ao desenvolvimento deste tipo de linguagem, dificultando assim a construção de um estatuto da profissionalidade docente.

Palavras-chave: Infância. Movimento. Profissionalidade docente. Formação Inicial. Educação Física.

\section{THE MOVEMENT LANGUAGE IN EARLY CHILDHOOD EDUCATION AND TEACHER PROFESSIONALISM CONSTRUCTION}

\begin{abstract}
This article, characterized as literature review, has the intention to contribute to reflections and discussions about the initial formation processes of Early Childhood Education teachers and the teaching profession construction, with the specific focus, in the language of movement, one of the necessary knowledge and indispensable to the teaching exercise in this educational level. According to authors like Pinto (2001), Cavalaro and Muller (2009), in the current context, teacher education courses for early childhood education have little or no discussion about the movement of the language. And yet, it is not established by the legislation to which professional is responsible for exercising the discipline of Physical Education in Early Childhood Education, related most closely to the development of this type of language, hindering the construction of a status of the teaching profession .
\end{abstract}

Keywords: Childhood. Movement. Teaching profession. Initial formation. Physical Education. 


\section{INTRODUÇÃO}

A infância, primeiros anos de vida, manifesta-se como uma etapa privilegiada e rica de aprendizagens; sendo a aprendizagem e a linguagem por meio do movimento tema de destaque neste artigo (FERREIRA; FREITAS, 2011). Ressaltamos que não ignoramos as demais aprendizagens e linguagens existentes na infância; contudo, faremos um recorte, uma vez que não seria possível argumentar acerca de todas nos limites deste artigo.

Discutir a linguagem do movimento na Educação Infantil e a constituição da profissionalidade especifica do docente da área remete-nos, primeiramente, partir nossa discussão sobre as concepções de infância que orientam o agir cotidiano e as práticas educativas presentes, principalmente, nos processos de formação do profissional docente.

A infância, por muito tempo, foi pensada como um estágio de fragilidade, dependência e de inferioridade e a criança caracterizada como um vir a ser, que não possui particularidades, um ser a-histórico (CORSARO, 2011).

Pereira (2011) aponta a necessidade da ruptura dessas concepções que ainda estão presentes em diversos cursos de formação de professores, orientando as práticas educativas de maneira errônea. Hoje, sabemos que a infância possui caráter múltiplo e plural, tem particularidades e singularidades próprias dependentes do contexto na qual está inserida e que a criança é um ser histórico, que produz e reproduz cultura, um ser do presente (CORSARO, 2011). Esta afirmação permite sustentar a ideia de que não existe apenas uma única matriz, ou seja, uma única infância, mas infâncias, com suas especificidades e necessidades diversas, expressada por meio de diferentes formas e contextos.

No contexto social brasileiro, a Educação Infantil, particularmente no âmbito da educação, têm adquirido prestígio no cenário da Educação Básica; tornando-se de grande relevância estudos nesta área para superação de concepções reducionistas de ensino e de infância presentes, especialmente, em processos de formação inicial docente (FERREIRA; FREITAS, 2011).

Pluralizar a infância, respeitar suas particularidades e autorizar a expressão nas suas singularidades, requer pensar em novas exigências que estão postas aos processos de formação inicial de professores, que irão orientar as práticas educativas e, consequentemente, desenvolver os saberes específicos necessários ao docente da Educação Infantil e a construção de sua profissionalidade (PEREIRA, 2011).

Dessa maneira, o objetivo deste artigo é contribuir com reflexões e discussões acerca dos processos de formação inicial de professores de Educação Infantil e da construção da profissionalidade docente, tendo como foco específico, a linguagem do movimento, um dos 
saberes necessários e indispensáveis ao exercício docente neste âmbito educacional.

\section{MEDOTOLOGIA}

A opção metodológica pautou-se na abordagem de cunho qualitativo, de caráter bibliográfico, visto que, a argumentação das discussões acerca do tema está "[...] desenvolvida com base em material já elaborado, constituído principalmente de livros e artigos científicos [...]" (GIL, 2002, p.44).

\section{RESULTADOS}

\subsection{AS LEGISLAÇÕES REFERENTES À EDUCAÇÃO INFANTIL E A LINGUAGEM DO MOVIMENTO CORPORAL}

Foi por meio da promulgação da Lei de Diretrizes e Bases da Educação Nacional (LDB) no 9394/96 que a Educação Infantil passou a ganhar espaço de relevância no cenário educacional brasileiro, em que lhe foi concedida a categoria de primeira etapa da educação básica.

De acordo com Martins, Garcia e Cardoso (2012) a LDB trouxe também mudanças significativas à formação de professores para Educação Infantil, visto que estabeleceu como requesito para atuação neste nível de ensino, a formação em nível superior; o que anteriormente não era exigido, e o atendimento institucional às crianças ficava sob tutela de professoras chamadas "normalistas", que tinham apenas formação em nível médio, ou de "pajens", que muitas vezes possuiam pouca ou nenhuma formação escolar.

De acordo com a LDB, respectivamente em seus artigos 29 e 30으, a Educação Infantil é a primeira etapa da educação básica, e tem como finalidade o desenvolvimento integral da criança até os seis anos de idade, em suas dimensões física, psicológica, intelectual e social, de maneira complementar a ação da família e da comunidade, é oferecida em "I - creches, ou entidades equivalentes, para crianças de até três anos de idade; II - pré-escolar, para as crianças de quatro a seis anos de idade".

Para tanto, esse espaço deve se caracterizar como um ambiente acolhedor e produtor de ricas e abundantes aprendizagens, visto que é nesse contexto que as crianças passam grande parte do dia, fora do ambiente familiar e onde se "inicia" o desenvolvimento da criança de maneira integral, em seus aspectos diversos. No entanto, para que isso aconteça, o corpo docente e demais profissionais atuantes nesse contexto, precisam estar preparados por meio de saberes específicos e indispensáveis para o exercício de sua profissão, para assim atender as especificidades e necessidades da infância e, proporcionar as crianças aprendizagens que 
viabilizem o desenvolvimento integral às mesmas.

O RCNEI (BRASIL, 1998, p.21) concebe a criança, assim como todo ser humano, como "um sujeito social e histórico e faz parte de uma organização familiar que está inserida em uma sociedade, com uma determinada cultura e um determinado momento histórico", rompendo com as visões reducuionistas vigentes em períodos anteriores.

Este documento oferece referências a realização do trabalho educativo do professor junto às crianças dessa faixa etária, considerando a pluralidade, as particularidades e necessidades da infância presente nos diversos contextos, de modo que favoreça a construção de práticas educativas as diferentes demandas de crianças existentes no país.

O RCNEI sistematiza seus conteúdos em eixos a serem desenvolvidos: Liguagem Oral e Escrita, Natureza e Sociedade, Racioncínio Lógico Matemático, Artes Visuais, Música e Movimento, com o objetivo de promover aprendizagens por meio da construção de diferentes linguagens pelas crianças.

O eixo Movimento, tema da central da discussão deste artigo, é descrito pelo RCNEI, como elemento importante na dimensão do desenvolvimento da cultura humana. $\mathrm{O}$ documento revela que é por meio do movimento que a criança se expressa, se comunica e interage, e que desde o nascimento ele está presente, sendo desenvolvido e apropriado.

o movimento humano, portanto, é mais do que simples deslocamento do corpo, no espaço: constitui-se em uma linguagem que permite às crianças agirem sobre o meio físico e atuarem sobre o ambiente humano, mobilizando as pessoas por meio de seu teor expressivo (BRASIL, 1998, p.15).

Entretanto, de acordo com Mello (2000), a linguagem por meio do movimento não pode se restringir a concepção orgânica e ambientalista do movimento, ou seja, ao desenvolvimento apenas de habilidades físicas, mas envolver também outros aspectos que englobam o cognitivo, o social, o afetivo, entre outros, sem dicotomizar corpo e mente. Para Mattos e Neira (1999) o movimento realizado pelas crianças carregam significados vinculados a intenções, racicínios e planos de ações, sendo por meio dele a maneira mais eficaz de se comunicarem, e também de produzirem e reproduzirem cultura.

Nesse sentido, consideramos fundamental argumentar acerca da formação inicial do professor de educação infantil - responsável direto pela mediação das aprendizagens por meio das diversas linguagens; os saberes desenvolvidos nos processos de formação e sua relação com a construção da profissionalidade docente.

Em relação específica, a linguagem do movimento está ligada a disciplina denominada 
Educação Física. Inicialmente, com a promulgação da LDB, em 1996, não havia nenhuma determinação sobre a obrigatoriedade da disciplina de Educação Física na Educação Básica. No entanto, a partir de 2001, após a modificação através da Lei № 10.328, a Educação Física foi estabelecida como componente curricular obrigatório, no artigo 26 , parágrafo 3 o da LDB, e também explícita no Parecer no 376/97, de 11/06/1997, do Conselho Nacional de Educação (CNE).

A Educação Física abrange um amplo conjunto de atividades e exercícios físicos, que vão para além dos esportes, mas que englobam ações do movimento humano em sua totalidade (OLIVEIRA; SILVA, 2005). Desse modo, podemos considerar o profissional de Educação Física como o principal responsável pelo ensino e orientação às práticas relacionadas à cultura do movimento humano.

Ainda na LDB, destaca-se que a Educação Física deve estar integrada à proposta pedagógica da escola e ajustada às especificidades da educação da criança e dos processos de escolarização nos seus diferentes níveis de ensino. Contudo, não é indicado nesse documento e nem no RCNEI a qual profissional compete lecioná-la na Educação Infantil e no Ensino Fundamental I, admitindo ao professor de Educação Infantil, sem formação específica em Educação Física, exercê-la. Sendo assim, é de suma importância que no processo de formação inicial dos professores de Educação Infantil sejam contempladas disciplinas que explorem temáticas relacionadas à linguagem por meio do movimento.

Entretanto, autores como Pinto (2001), Cavalaro e Muller (2009) apontam que no contexto atual, os cursos de formação de professores para a Educação Infantil apresentam pouca ou nenhuma discussão acerca da linguagem do movimento; não contemplando em sua matriz curricular disciplinas relacionadas à expressão, linguagem ou cultura do movimento; quando existentes, enfatizam aspectos instrumentais, biológicos, ambientalistas ou apenas psicomotores, como por exemplo, os conteúdos trabalhados em disciplinas de Psicologia da Educação.

Dessa maneira, a problemática fixa-se e agrava-se na inexistência de experiências e vivências significativas, de competências e saberes específicos relacionados à linguagem do movimento, necessários e de essencial relevância na formação docente, tanto para o desenvolvimento integral da criança, quanto para a própria construção de sua profissionalidade.

De acordo com o pensamento de Pinto (2001), a formação inicial de professores de Educação Infantil pode (e precisa ao nosso olhar) constituir-se em um tempo de desalienação do movimento e de expressões lúdicas por meio das diversas linguagens, um espaço em que seja possível vivenciar, conhecer e refletir sobre as diversas linguagens de modo significativo, em 
especial destacado neste artigo, a linguagem do movimento, tendo em vista a futura ação do profissional que se forma e, acrescentamos ainda, da construção de sua profissionalidade.

\section{DISCUSSÃO}

\subsection{A CONSTRUÇÃO DA PROFISSIONALIDADE DOCENTE}

No contexto atual, cerne das reformas educacionais, faz-se necessário repensar os modelos de formação inicial docente; uma vez que os saberes e competências específicos, minimamente necessários, precisam ser desenvolvidos em processos formativos, como pontapé inicial, para futuro exercício e ação profissional docente e para a construção de sua profissionalidade, tendo como ponto de partida, o docente como produtor de sua identidade profissional e a busca pelo reconhecimento social de sua profissão.

Existem hoje, muitos teóricos (SACRISTÁN, 1991; NÓVOA, 1991; ROLDÃO, 2005; CARDONA, 2006), que discutem acerca da natureza e dos caracterizadores da profissionalidade docente, com objetivo de identificar aquilo que se caracteriza como profissão, diferindo-a de outras formas de prestação social de serviço, "tais como o ofício, o trabalho técnico, ou o de funcionário" (ROLDÃO, 2000).

Nesse sentido, de modo breve, mas ao mesmo tempo amplo, a profissionalidade pode ser definida "como um conjunto de atributos, socialmente construídos, que permitem distinguir uma profissão de outros muitos tipos de actividade, igualmente relevantes e valiosas" (ROLDÃO, 2005, p.108).

Em especial a profissionalidade docente, Sacristán (1991, p.65) entende que é um "conjunto de comportamentos, conhecimentos, destrezas, atitudes e valores que constituem a especificadade do ser professor".

Roldão (2000) define alguns caracterizadores de profissionalidade: a função, o saber, a reflexividade, o poder e a cultura profissional. Com o intuito de analisar e compreender a profissionalidade docente e seu processo de construção, iremos percorrer e discorrer sobre estes caracterizadores, e a presença dos mesmos nos processos de formação inicial de professores no contexto atual.

Como primeiro elemento caracterizador de profissionalidade, temos a função, o que nos remete a dizer que o profissional é aquele que possui uma função socialmente reconhecida, distinguindo-o dos demais profissionais e dando-Ihe individualidade social. Todavia, o que temos visto tanto na profissão docente como nos cursos de formação inicial de professores, é a falta de clareza quanto a este elemento. Em alguns contextos atribui-se ao docente a função formativa e 
pedagógica de maneira global, e em outros, concebe-se o docente como especialista, aquisitor e transmissor de determinados conteúdos e saberes (ROLDÃO, 2000). Para Roldão (1998), o que distingue e caracteriza de maneira efetiva o professor, profissionalmente, é a função de ensinar, de modo que faça alguém aprender alguma coisa.

Para o desempenho de sua função o profissional docente precisa, necessariamente, dominar o saber específico, segundo elemento caracterizador de profissinalidade, indispensável ao exercício da docência. Os saberes necessários para a função de ensinar perpassam aspectos científicos, metodológicos, práticos, e acrescentamos aqui, pedagógicos, que quando articulados se convertem em saber educativo, sendo assim de fundamental importância o desenvolvimento destes saberes nos processos de formação inicial docente para sua futura atuação profissional (ROLDÃO, 2000).

Ligada à função e ao saber, a reflexividade, atribuída socialmente ao profissional e terceiro elemento constituinte da profissionalidade, permite ao indivíduo agir de modo coeso no exercício de sua profissão, partilhando interesses e reinvidicações, mas para além, se afirmando como ser ativo em uma comunidade profissional, como produtor de um saber específico. Podemos também encontrar no âmbito educacional, a ambiguidade do estatuto do professor enquanto comunidade, “ora se reclamam detentores do saber científico das áreas que leccionam (disciplinas) ora invocam a supremacia do saber pedagógico puro, tomado equívoco o seu campo de afirmação como profissionais" (ROLDÃO, 2000. p.5), fato encontrado não somente na profissão em si, mas desde os processos de formação que muitas vezes acabam priveligiando alguns saberes, relegando outros a segundo plano - como no caso a linguagem do movimento, tema de destaque neste artigo; dificultando a afirmação do futuro docente em uma comunidade profissional.

Outro elemento definidor de profissionalidade está relacionado ao poder de decisão sobre sua própria ação. Segundo Roldão (2000, p. 5) espera-se que o profissional "decida sobre a sua acção, com base no conhecimento específico que é suposto deter, e por isso é individualmente responsável, no enquadramento da sua comunidade profissional". Contudo, quanto ao poder de decisão dos professores, também encontramos hoje um estatuto ambíguo, sendo constituído por elementos de grande dependência - como por exemplo decisões curriculares; e outros com "liberdade" de decisão e ação como a atuação docente direta (ROLDÃO, 2000).

No que diz respeito a uma comunidade profissional, temos também como útlimo elemento constituinte da profissionalidade a pertença e adoção de uma cultura profissional, "caracterizada pela produção e partilha de saberes e afirmação colectiva do grupo profissional" (ROLDÃO, 2000, p.6), manifestação esta não encontrada no âmbito docente e que em nossa concepção poderia ser 
instigada desde os processos de formação inicial. Por tudo isso, Roldão $(2000$, p.6) afirma:

parece assim poder reconhecer-se que os docentes são um grupo de actividade marcado por indefinições e ambiguidades de estatuto, a caminho de um reforço da dimensão de profissionalidade, mas ainda constrangido por lógicas que a inviabilizam ou, pelo menos dificultam.

Para além dos caracterizadores da profissionalidade, em relação específica a construção da profissionalidade docente, Roldão (2005, p. 117) acrescenta que o que de fato caracteriza o ofício do professor é o ato de ensinar algo a alguém, e que este alguém aprenda de maneira efetiva como já destacado anteriormente, e para que ocorra esta ação "requer um vasto conjunto de saberes científicos, no campo da educação, e está longe de ser espontâneo ou resultar automaticamente do domínio do conteúdo a ensinar", o que nos remete a dizer que é preciso resignificar a essência do ensinar que por meio de um processo histórico foi construído e permanece enraizado na prática docente, com a intenção de assim iniciarmos uma longa caminhada rumo à construção de um estatuto da profissionalidade docente.

\section{CONCLUSÃO}

Para que o estatuto da profissionalidade docente se construa é preciso primeiramente que o docente se constitua como profissional, dotado de saberes e conhecimentos específicos requeridos pelo ofício de sua função, além do desenvolvimento dos caracterizadores da profissionalidade definidos por Roldão (2000): a função, o saber, a reflexividade, o poder e a cultura profissional, que quando presentes primeiramente no processo de formação inicial exercem fundamental importância para a construção da profissionalidade docente, que se estende na prática cotidiana de seu ofício e na formação continuada.

Especialmente para a construção da profissionalidade do professor de Educação infantil, temos como pontos de partida a clareza da concepção de criança e infância, sua função social, política e pedagógica. Para isso é de fundamental importância que o professor tenha conciência plena do processo de ensino aprendizagem: para quem, o que, por que e para que ensina determinados conteúdos como, por exemplo, tema de destaque neste artigo, a linguagem do movimento.

Cabe destacar que o profissional de Educação Física é o principal indíviduo capacitado em seu processo de formação para atuar especificamente com as diversas linguagens do movimento que irão contribuir para a formação integral do ser humano. Todavia, devido as lacunas existentes nas políticas públicas, que não estabelece a que profissional compete lecionar a disciplina de 
Educação Física na Educação Infantil e no Ensino Fundamental I, admiti-se ao professor de Educação Infantil, sem formação específica em Educação Física, exercê-la. Sendo assim, é de suma importância que no processo de formação inicial dos professores de Educação Infantil sejam contempladas disciplinas que explorem temáticas relacionadas à linguagem por meio do movimento.

\section{REFERÊNCIAS}

BRASIL. Ministério da Educação e Cultura. Lei de Diretrizes e Bases para a Educação Nacional. no 9394/96. Brasília: MEC/FAE, 1996.

BRASIL. Ministério da Educação. Conselho Nacional de Educação. Parecer 376/97. 1997.

BRASIL. Secretaria de Educação Fundamental. Referencial Curricular Nacional para a Educação Infantil/ Ministério da Educação e do Desporto. Volumes 1, 2 e 3, Brasília: MEC/SEF, 1998.

BRASIL. Apreciação do Referencial Pedagógico Curricular para a Formação de Professores da Educação Infantil e das Séries Iniciais do Ensino Fundamental. Parecer CNE/CEB no 4/1999, aprovado em 6 de abril de 1999.

BRASIL. Plano nacional de educação. Brasília: INEP, 2001.

CARDONA, M. J. Educação de Infância: Formação e Desenvolvimento Profissional. Chamusca: Editora Cosmos. 2006.

CAVALARO, A. G.; MULLER, V. R. Educação Física na Educação Infantil: uma realidade almejada. Revista Educar. Curitiba: Editora UFPR, n.34, p.241-250. 2009.

COLÉGIO BRASILEIRO DE CIÊNCIAS DO ESPORTE (CBCE). Fórum sobre formação profissional na Educação Física brasileira: documento síntese. Campinas, 2 de março de 2002. Disponível em: <http://www.cbce.org.br>. Acesso em: 3 set. de 2013.

CORSARO, W. A. Sociologia da infância. 2ae ed. Trad. Lia Gabriele R. Reis.; Rev. Tec: Maria Letícia B. P. Nascimento. Porto Alegre: Artmed. 2011.

FERREIRA, M. C. P. de L.; FREITAS, R. A. M. da M. O lugar da Educação Física na Educação Infantil. Anais: IV EDIPE - Encontro Estadual de Didática e Prática de Ensino. Goiânia, GO. 2011. Disponível em: http://www.ceped.ueg.br/anais/ivedipe/pdfs/educacao_fisica/co/383-865-1-SM.pdf. Acesso em: 21 de maio de 2014.

GIL, A. C. Como elaborar projetos de pesquisa. 4. ed. São Paulo: Atlas, 2002.

MARTINS, F. de P.; GARCIA, I. G.; CARDOSO, R. A profissionalidade docente na Educação Infantil. Anais: VI COPEDI - Congresso Paulista de Educação Infantil e II Congresso Internacional de Educação Infantil | "Educação Infantil subvertendo ordens? Política, imaginação e fantasia". São Paulo, SP. 2012. Disponível 
em:http://www3.fe.usp.br/secoes/inst/novo/agenda_eventos/inscricoes/PDF_SWF/13983.pdf. Acesso em: 21 de maio de 2014.

MATTOS, M. G. De \& NEIRA, M. G. Educação Física Infantil: construindo o movimento na escola. 3. ed. São Paulo: Phorte Editora. 1999.

MELLO, M. A. Educação Infantil e Educação Física, um binômio separado pelo movimento, mas qual movimento? Anais: 23a Reunião Anual da Associação Nacional de Pós-Graduação e Pesquisa em Educação - $\quad$ ANPED, Caxambu. 2000. Disponível em: <http://168.96.200.17/ar/libros/anped/0711P.PDF> Acesso em: 15 de novembro de 2008.

NÓVOA, A. (org). Profissão Professor. Porto: Porto Editora. 1991.

OLIVEIRA, Aurélio Luiz de; SILVA, Marcelo Pereira da. O profissional de educação física e a responsabilidade legal que o cerca: fundamentos para uma discussão. In: SIMPÓSIO INTERNACIONAL PROCESSO CIVILIZADOR, 9., 2005, Ponta Grossa. Comunicação Oral. Ponta Grossa: CEFET-PR. Disponível em: <http://www.pg.utfpr.edu.br/ ppgep/Ebook/cd_Simposio/artigos/comunicacao_oral/art4.pdf>. Acesso em: 3 abr. 2013.

PEREIRA, V. A. Leituras de infância e sujetividade: desafios à profissionalização do professor de crianças no contexto do pensamento pós-metafísico. In: Guimarães, C. M.; Reis, P. G. R. dos (org.) Professores e infâncias: estudos e experiências. Araraquara, SP: Junqueira\&Marin. 2011.

PINTO, R-M. N. A formação de professores para Educação Infantil: Desafios para a Universidade. (Resenha) Revista Pensar a Prática. v.4. 2001.

ROLDÃO, M. C. Que é ser professor hoje? - a profissionalidade docente revisitada. Revista da ESES, 1, Nova Série, p. 79-88. 1998.

ROLDÃO, M. C. Formar professores - Os desafios a profissionalidade e o currículo. Brochura publicada pela Universidade de Aveiro. Semana da Prática Pedagógica, Outubro. 2000.

ROLDÃO, M. C. Profissionalidade docente em análise - especificidades do ensino superior e não superior. Revista Nuances: estudos sobre a educação. Ano XI, v.12, n.13, jan/dez, p.106-126. 2005.

SACRISTÁN, J. G. Consciência e acção sobre a prática como libertação profissional dos professores. In: Nóvoa, A. (org). Profissão Professor. Porto: Porto Editora. 1991. 